\title{
E-COLLABORATIVE TASKS AND THE ENHANCEMENT OF WRITING PERFORMANCE AMONG IRANIAN UNIVERSITY-LEVEL EFL LEARNERS
}

\author{
Nazli AZODI \\ ORCID: 0000-0002-5738-977X \\ Department of Foreign Languages \\ Isfahan (Khorasgan) Branch Islamic Azad University \\ Isfahan, IRAN \\ Ahmadreza LOTFI \\ ORCID: 0000-0002-3760-2430 \\ Department of Foreign Languages \\ Isfahan (Khorasgan) Branch Islamic Azad University
}

Isfahan, IRAN

Received: 12.02.2019 Accepted: 19.03.2019

\begin{abstract}
The prevalence of using social software in foreign and second language settings has caused a resurgence of interest in collaborative writing. This study investigates the benefits of collaborative and e-collaborative tasks on writing performance of the students in a process-oriented approach. It, in fact, examines the effects on the accuracy, complexity, and fluency of the written text produced by the learners. To this end, the quasiexperimental design was employed and 74 intermediate students at Islamic Azad University (Isfahan Branch) in Iran participated in the study. They were divided into three groups by random assignment in which two experimental groups were required to perform their tasks in collaboration while only one of them had access to Telegram Application outside the classroom. The control group followed the conventional method of learning how to write. The Measures of One-way ANCOVA, having compared the pretests and posttests results, showed a significant change in the accuracy and complexity of the written texts produced by the students in the experimental group applying e-collaboration. It also revealed that there was no significant change in the fluency of the written texts produced by the students.
\end{abstract}

Keywords: Collaborative writing, e-collaborative writing, process writing, writing performance

\section{INTRODUCTION}

For EFL/ESL learners, the ability to write effectively in the target language is an important skill and an essential productive activity (Hussin et al., 2015) and it is also believed to become more and more important around the world (Weigle, 2002; Ghoorchaei, Tavakoli, \& Nejad Ansari, 2010). It is necessary to bear in mind that teaching English L2 writing differs from other skills given the fact that it is generally employed as a support skill in language learning as well.

In general, there are four approaches for teaching and learning writing, namely, "product-focused approach", "process-focused approach", "genre-based approach", and "process and genre based approach". Product-based approach, which is a traditional one, provides the learner a model and the learners need to mimic it in order to generate a similar product. This approach is teacher-centered and its proponents believe that it enhances students' writing proficiency (Ghufron, 2016). The process-focused approach, which is the approach applied in this study, focuses on how a text is written rather than the final outcome. The teacher in a processapproach classroom becomes the facilitator. In such classrooms, writing is essentially learnt, not taught. 
Similar to the product-focused approach, genre-based approach views writing as predominantly linguistic. The genre approach, however, places a greater emphasis on the social context in which writing is produced (Hyland, 2003). Finally, the Process-Genre approach is a combination of process approach and genre approach. The proponents of this approach propose that Process-Genre Approach regards writing as a process which includes knowledge of language, knowledge of the context and purpose (as in genre approach), and skills in using language. This approach allows the students to study the relationship between purpose and form for a particular genre as they use recursive processes of prewriting, drafting, revision, and editing.

This research applied the process based approach, which in turn has had different models, namely the Schmidt model, the Van Galen model, the Hayes and Flower model, and the Hayes model (Gunes, 2007). Flower and Hayes (1981) proposed that the writing product must be improved during the writing process. They introduced three dimensions of the act of writing which later refined by Hayes (1996). After that, different stages of the process writing approach have been presented similarly with some differences in order that had been proposed by Flower and Hayes (1981). They emphasized multiple stages of the writing process, such as prewriting, drafting, revising, editing, and publishing. This writing process is dynamic and recursive in nature. Therefore, these stages are considered as essential parts of teaching writing skill in order to produce a text. However, working precisely on each stage might be refused by some teachers in their classrooms due to the time it demands, and some others believe it does not emphasize on teaching grammatical accuracy (Leki, 1991). Besides, teacher-led process activities may fail to accommodate individuals' learning of selfregulation so as to develop their writing skills.

Another instrumental discussion in language skills is what social constructivists maintain. According to Vygotsky (1978), learning is a social activity and it can be developed through social interactions. As far as teaching writing is concerned, such social interaction among learners can be provided by group or collaborative activities in the class. Collaborative writing entails the production of a shared document where group members engage in substantive interaction, shared decision-making and responsibility for the document (Allen, 1987). Additionally, Vygotsky's (1978) idea of the zone of proximal development plays a significant role in understanding how collaborative learning occurs. Based on this theoretical framework, the group work or pair work for collaborative writing is in accord with social constructivists' points of view. According to them, the assistance of the partner in such collaborative activities are called scaffolding.

On the other hand, the group work in the classroom might be a tough task for learners. Leki (2001) believed that the learners are concerned about both more competent partners and others' attitudes in a group and they wonder how much they can contribute to the group. By the advent of the Internet over the past two decades, and by its penetration into educational contexts, language learners are provided with new opportunities to be able to interact with each other, a key factor in developing language skills from a sociocultural view of learning (Vygotsky, 1986; Bronckart, 1995). Recently, nearly all language learners have experienced online communications due to its popularity in educational settings, especially for language learning. Rybushkina \& Krasnova (2015) underscored the influential role online learning can play in the field of EFL/ESL writing. According to them, the conventional face-to-face learning environment might not be suitable for all students because every single learner has different learning abilities. Nevertheless, some learners and some teachers have faced many different problems while learning and teaching writing skill such as time constraints, inadequate facilities to support writing as well as lack of motivation which can be solved by Internet-based pedagogy and online learning environments (Krasnova \& Ananjev, 2015; Cahyono \& Mutiaraningrum, 2016).

As far as language learning is concerned, online communication enhances learners' access to comprehensible input, and then they can have more opportunities to practice language production. It should be added that such exercises are of great help for those who learn English as a foreign language. Over the past few decades, many research studies used blended learning and collaborative writing to enhance writing performance. Some researchers have investigated the effectiveness of blended learning in ESL/EFL writing skill (Adas \& Bakir, 2013; Keshta \& Harb, 2013; Shafiee et al., 2013; Arslan, 2014; Abdulmajid, 2014). Other researchers had also studied how using collaborative learning improves writing (Al-Ahmad, 2003; Taki \& Fardafshari, 2012; Jafari \& Ansari, 2012; Grami, 2012; Shukor \& Noordin, 2014). Results of these studies indicated that blended learning and collaborative learning enhance students' writing performance. 
Moreover, similar studies investigated the role of collaboration in the context of the present study. One research examined the effect of collaborative interaction on the development of writing skill in a homogeneous and heterogeneous context which showed a significant improvement in both groups after applying collaborative interactions among learners (Maftoon \&Ghafoori, 2009). Another study investigated the effect of group work on writing accuracy based on gender. The results revealed that the students in the collaborative writing group outperformed the students with no collaboration and it also showed that the females in the group outperformed the males (Jafari \& Nejad Ansari, 2012). Another research studied the effect of collaborative activities on the writing performance of Iranian intermediate EFL learners in the textbook evaluation course. The research showed that the students working in groups outperformed those writing individually based on such writing components as content, organization, grammar, and vocabulary (Hosseinpour \& Biria, 2014).

Additionally, other researchers in the field examined the effects of CMC in collaborative tasks. For example, one study investigated the effect of weblogs on the improvement of Iranian EFL learners' writing skill which found that the blog helped them to improve their writing through the collaborative learning environment that was established and through the process of writing that was adopted (Dalir, Jafarigohar, \& Soleimani, 2013). The other research in this area investigated the effect of participation in an online discussion forum on writing performance and attitudes of Iranian EFL learners which showed a significant development in both aspects after the group work (Gorbanpour, 2013).

The studies reviewed here have operationalized collaborative writing tasks as tasks completed in pairs. Some of them investigated these tasks with the assistance of weblogs or online discussion forums as scaffolding from a sociocultural perspective. On the other hand, research findings on collaborative writing are mostly limited to the beginning stages of writing process which are pre-writing activities such as planning and brainstorming. Besides, most research focused on the product of writing rather than the process of writing. Thus, the process of writing has remained a private act, where writers are left alone to their devices when they are about to make important decisions. It should be noted that studies on collaborative writing have, by and large, focused on the attention to language and the socio-cognitive processes evident in such interactions. The nature of the writing process and the nature of the final written text have received scant attention.

This study attempted to emphasize on the nature of process writing and tried to investigate how technological advances such as social networking applications could help improve collaborative writing in more effective ways. These applications such as Telegram, Whatsapp, and Wechat are online platforms which enables people to communicate in order to share personal or career interests and activities. Since most young learners are dependent on their smartphones, we can take advantage of such devices and encourage them to interact more with their peers. On the other hand, using such devices helps students to be in permanent contact with the members of their group and their teacher. The teacher can provide them useful resources based on students' problems when they are not in class.

To this end, this study aimed at examining the efficacy of applying online application devices, which was Telegram Instant Messaging Service, to enhance collaborative writing skills among Iranian undergraduate English students. The study attempted to measure the level of learners' writing performance as far as the complexity, accuracy, and fluency of the writing are concerned. The research question that guide the study are:

1. Does collaborative writing have any significant effect on the Iranian EFL learners' writing performance?

2. Does implementing online application devices for enhancing collaborative writing in an E-learning project have any significant effect on the Iranian EFL learners' writing performance?

Therefore, it was hypothesized that implementing online application devices which enhances collaborative writing does not have any effect on the Iranian EFL learners' writing performance. In addition, it was hypothesized that collaborative writing has no effect on the performance of Iranian EFL learners' writing.

\section{METHOD}

The study was designed in a quasi-experimental method, and it was conducted with three groups i.e., one control group and two experimental groups. The study aimed at investigating the effects of collaborative and e-collaborative tasks on the learners' writing performance. The control group followed the conventional 
method of teaching how to write. While one experimental group was provided by collaborative tasks in the class, the other experimental group experienced collaborative and e-collaborative tasks. The participants were majoring English Translation at Islamic Azad University, Isfahan Branch, and the research were carried out in a 2 hours writing course held once a week. All three groups were instructed to write Comparison-Contrast, Cause-Effect, and Classification essay following a process-oriented approach.

\section{Participants}

A total of 74 students participated in the project; 55 were female and 19 were male, and their age ranged from 21 to 29 years old. All the subjects majored in English Translation at Islamic Azad University (Isfahan Branch) in Iran. All of them had Persian as their L1, and they had studied English as their first foreign language in mainstream education; furthermore, they had learned the preliminaries of writing in another course two academic years before. Formally, the subjects were expected to represent intermediate level language learners (in the range of $\mathrm{B} 1$ on the CEFR scale). Although, it is, naturally, probable that some subjects may have been more proficient writers than the others, their university grades represented their overall skills. The selection of experimental and control groups has been done by random assignment. The study was done in the first and the second semester of the academic year 2017 and 2018. All the subjects in the three groups learned how to write the introductory, body, and concluding paragraphs of an essay as a process. They also learned how to write Comparison-Contrast, Cause-Effect, and Classification essays.

This study required three groups; namely one control and two experimental groups. The subjects in one experimental group were asked to use an online device; applying e-collaborative tasks. To make sure that the subjects in that experimental group have no problems in using the Internet, they were asked before the treatment to check if they access smartphones and, moreover, they were clarified how to use Telegram Instant Messaging Service during the project. As all the subjects had sufficient techno-literacy in this regard, they did not need special instruction. Furthermore, the other experimental group had to write collaboratively in the class to which most learners were familiar. Nevertheless, the researcher explained the learners how to write in a group following the process approach in details.

\section{Procedure}

As it is mentioned above, the selection of the three groups; namely two experimental groups (EG1 \& EG2) and one control group (CG) has been done by random assignment. This study utilized several sets of data to address the research questions including pretest, posttest, Telegram Instant Messaging Service (Telegram Application), and three evaluation tools. The detailed procedure is explained in the following section.

\section{Data Collection Procedures}

At first, the pretests were administered to capture the initial differences among the participants to experimental groups before the treatment and to the control group at the beginning of the course. The pretest was a timed essay writing in which the students had to write an in-class essay within 50 minutes. To this end and in order to provide content validity for the study, three topics were given to students and they were required to select one topic and write an essay of 250 words. In order to select the writing topics, a variety of factors were taken into account (i.e., topics were neither too simple nor too difficult, they did not require specialized knowledge, and the topics were selected from everyday issues). Since these three topics revolved around participants' life and society, it was hoped that they would have stimulated participants to write enthusiastically.

The second step of the study was administering the posttests which learners in all three groups took a writing test, an essay writing with three selective topics similar to that of the pretest at the end of the courses. The purpose was to check if there was any significant difference between the average scores of the three groups' performance on writing test, and if the treatment had any effect on the writing proficiency of the learners in experimental groups. This test was also designed to find out the extent of advance in the control group who received the traditional classroom-based writing instruction. 
Another part of the procedure of the project is utilizing Telegram Application. The learners in one of the two experimental groups (EG1) needed to apply an online device to share and assist the members of their group to complete their writing assignments when they were not in the class. Since the aim of this study was to estimate if using online application devices would improve learners' collaborative writing to write more proficiently, these learners had this chance of writing in a group even when they were out of the class setting. This application was selected for several reasons. First of all, this application facilitates its users by providing the chance to share and access files and documents safely. Secondly, it can be installed both on cell phones and laptops or computers.

The students participated in the control group were asked to complete their writing tasks both in the class and at home individually without any assistance. However, those who participated in the experimental groups were required to form groups of three member in order to do their writing tasks. The students were free to select their partners in their groups to avoid anxiety or interpersonal problems among the members. The main difference between the two experimental groups was using Telegram Application in one of them which enabled them to be involved in e-collaborative tasks. In fact, the researcher created a group in this application named Essay Writing Community which enabled its users to share and read writing assignments while they were away from the class environment.

Following the process-based approach in writing, the EG1 participants were asked to brainstorm on the topic introduced by the researcher in the class and to organize their ideas in their groups in order to perform the first stage, prewriting. Then, while the subjects were at home, one member in each group wrote the first draft and shared it on the Telegram so that all other students were able to read the written assignment. After that, the second member of each group had to revise the text and send it on the Telegram. Next, the last member of each group had to edit the text with similar procedure. Now, the researcher as the instructor of the class commented on this written assignment and shared it on the Telegram. At last, each group wrote their final draft in the class based on the received comments. The participants were required to switch their roles as writer, reviser, and editor every week for each writing assignment. The writing stages and activities are illustrated in Figure 1. All the stages repeated every week for each assignment. A sample of group activities in Telegram Application presented in Appendix.
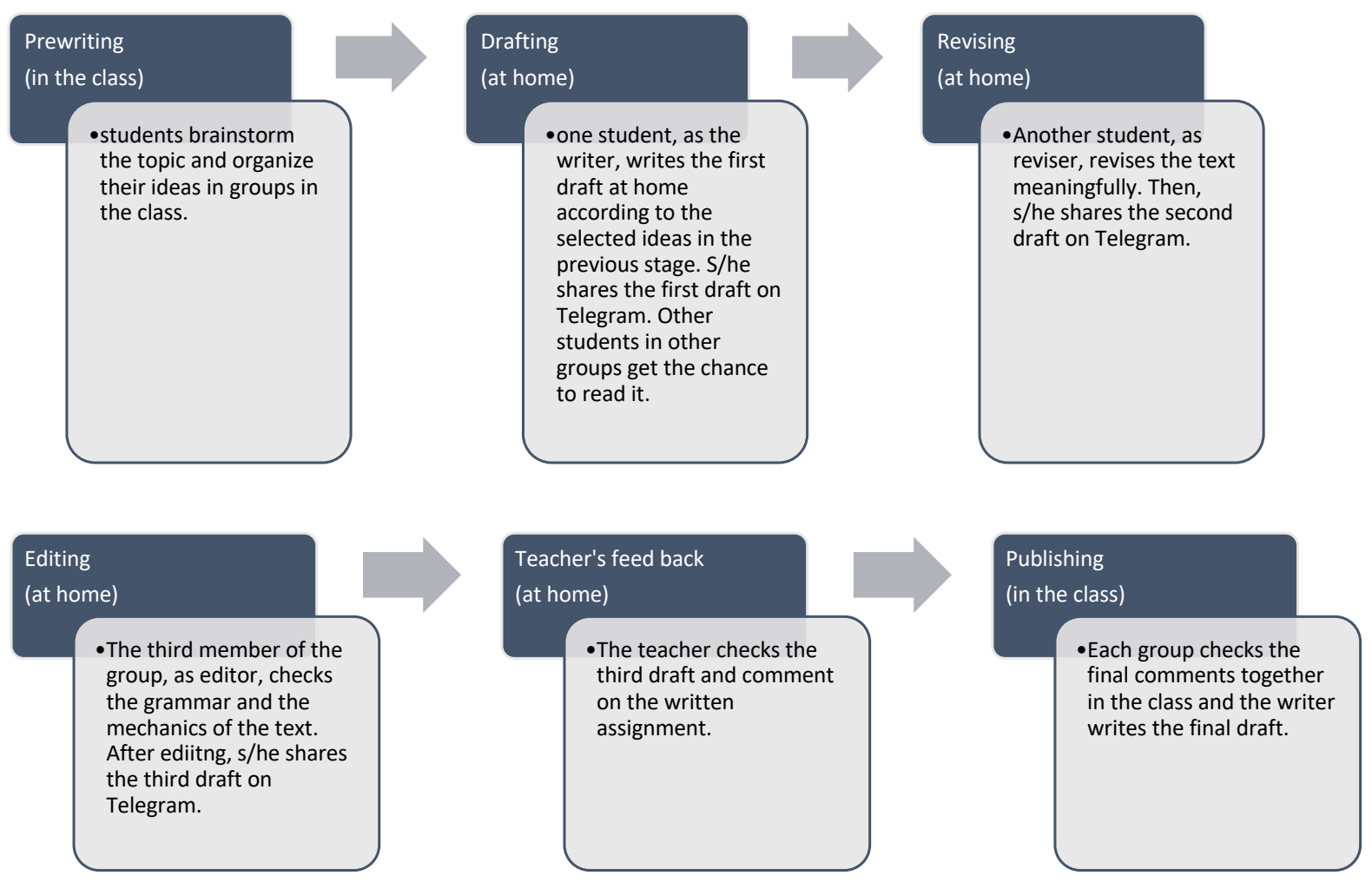

Figure 1. Procedures of the EG1 (e-collaborative tasks) 


\section{Rating Procedures}

The last step of this research is the one used for evaluating the pretests and posttests. This study aimed at detecting any changes on writing performance of the participants after collaboration and using Telegram Application. In order to assess participants' writings to evaluate their skills and writing performance, measures of accuracy, complexity, and fluency were used. Accuracy reflects grammatical and lexical correctness and the L2 learners' effort to control attentional resources in order to avoid errors, while complexity entails more elaborated language, that is, the effect of risk taking and "restructuring" language (Ellis, 2009). On the other hand, fluency refers to the number of words and the use of academic words in the writing. To evaluate three aspects of the participants' writing performance:

Accuracy: a list of 10 grammatical errors adopted from Ferris (2006) were used. The category includes verb tense, verb form, subject verb agreement, articles/determiners, non-endings, pronouns, fragments, run-ons, word choice, and miscellaneous errors.

Complexity: the number of subordinate clauses made by each participant were counted per 100-word text.

Fluency: the total number of words written were counted and divided by the total number of minutes it took them to write the task which was 50 in this study.

The essays were rated by two competent raters based on these rating criteria, and in order to check the interrater reliability consensus statistically the Pearson product Moment Coefficient Correlation were used (Table 1). As can be seen in the Table 1, all correlations were greater than .70 which made the result satisfactory. The raters, the researcher herself and another colleague with the experience of teaching Essay Writing course at university for 15 years, evaluated the pretests and posttests of the participants.

Table 1. Inter-rater reliability of the raters

\begin{tabular}{llll}
\hline & Pearson Coefficient & Correlation & \\
\hline & $\mathrm{EG} 1$ & $\mathrm{EG} 2$ & $\mathrm{CG}$ \\
\hline $\begin{array}{l}\text { Pretest } \\
\text { Rater1/Rater2 }\end{array}$ & .82 & .86 & .80 \\
\hline $\begin{array}{l}\text { Posttest } \\
\text { Rater1/Rater2 }\end{array}$ & .85 & .87 & .86 \\
\hline
\end{tabular}

\section{Data Analysis Procedure}

Data analysis was performed in light of the research questions of this study: a. Does collaborative writing have any significant effect on the Iranian EFL learners' writing performance? b. Does implementing online application devices for enhancing collaborative writing in an E-learning project have any significant effect on the Iranian EFL learners' writing performance?

The three groups took the pretest, and the experimental groups were subsequently exposed to their relevant treatments, that was collaborative activities both in the class and at home, while the learners in the control group attended their regular classes bereft of collaborative activities either in the class or at home. At the end of the study, a posttest was administered to gauge the development of the participants in the experimental and control groups with respect to their writing performance. To come up with the results of the comparisons of the scores of the learners in the three groups, one-way ANCOVA was conducted; ANCOVA makes comparisons among the posttest scores of the (three) groups while controlling for any potential pre-existing differences on the pretest. 


\section{RESULTS}

This part provides the outcome of the analysis of the collected data. The scores in the three groups were compared based on the three aspects of their writing performances which are accuracy, complexity, and fluency.

\section{L2 Writing Accuracy}

The results of the comparison of the three groups on the posttest scores of accuracy are displayed in tables

Table 2. Descriptive statistics results comparing EG1, EG2, and CG on accuracy posttest scores

\begin{tabular}{ccccc}
\hline Groups & Mean & Adjusted Mean & Std. Deviation & $N$ \\
\hline EG1 & 4.63 & 4.81 & 2.23 & 29 \\
EG2 & 6.32 & 6.44 & 3.29 & 25 \\
CG & 12.70 & 12.29 & 8.08 & 20 \\
\hline Total & 7.38 & 7.84 & 5.79 & 74 \\
\hline
\end{tabular}

As it could be seen in Table 2, the accuracy posttest mean scores of the EG1 $(M=4.63)$, EG2 $(M=6.32)$, and CG $(M=12.70)$ differed from one another. Regarding these mean scores, reminding one important point is in order: as it was explained before, the accuracy scores of the participants were computed by counting the number of different types of errors (e.g., subject-verb agreement, noun ending, articles/determiners, verb tenses, verb forms, fragments, run-on sentences, pronouns, and diction) in their writings; thus, the lower the score, the lower the number of the errors s/he made (and thus the more accurate the learner). This means that the EG1 learners $(M=4.63)$ were more accurate than EG2 learners $(M=6.32)$, who were, in turn, more accurate than the CG learners $(M=12.70)$. To find out whether the differences among these accuracy posttest mean scores were of statistical significance or not, the researcher had to look down the $p$ value in front of the Groups row under the Sig. column Table 3.

Table 3. Results of one-way ANCOVA for comparing EG1, EG2, and CG on accuracy posttest scores

\begin{tabular}{lllllll}
\hline Source & $\begin{array}{l}\text { Type III Sum of } \\
\text { Squares }\end{array}$ & $d f$ & Mean Square & $F$ & Sig. & $\begin{array}{l}\text { Partial Eta } \\
\text { Squared }\end{array}$ \\
\hline Corrected Model & 1869.14 & 3 & 623.04 & 74.40 & .00 & .76 \\
Intercept & 11.02 & 1 & 11.02 & 1.31 & .25 & .01 \\
Pretest & 1056.95 & 1 & 1056.95 & 126.22 & .00 & .64 \\
Groups & 693.13 & 2 & 346.56 & 41.38 & .00 & .54 \\
Error & 586.13 & 70 & 8.37 & & & \\
\hline Total & 6491.25 & 74 & & & & \\
\hline Corrected Total & 2455.27 & 73 & & & & \\
\hline
\end{tabular}

Table 3 depicts that there was a statistically significant difference in accuracy posttest mean scores for the three groups because the $p$ value under the Sig. column and in front of the Groups row was smaller than the pre-specified level of significance $(.00<.05)$. To find out the exact locations of the three groups' differences, the Bonferroni post hoc test was conducted, the results of which are displayed in Table 4. 
Table 4. Results of the bonferroni post hoc test for comparing EG1, EG2, and CG on accuracy posttest scores

\begin{tabular}{lllllll}
\hline Groups & & Mean Difference & Std. Error & Sig. & \multicolumn{2}{c}{ 95\% Confidence Interval } \\
\hline \multirow{2}{*}{ EG1 } & & & & Lower Bound & Upper Bound \\
\hline \multirow{2}{*}{ EG2 } & EG2 & -1.62 & .79 & .12 & -3.56 & .30 \\
& CG & $-7.48^{*}$ & .84 & .00 & -9.54 & -5.41 \\
\hline \multirow{2}{*}{ CG } & EG1 & 1.62 & .79 & .12 & -.30 & 3.56 \\
& CG & $-5.85^{*}$ & .86 & .00 & -7.98 & -3.72 \\
\hline
\end{tabular}

From Table 4, it could be inferred that (a) the difference between EG1 and EG2 was not statistically significant although EG1 learners were more accurate than EG2 learners in their writings on the posttest, and (b) CG learners were significantly different from both EG1 and EG2 learners; that is, they were significantly less accurate than the EG1 and EG2 learners. These results are also graphically shown in the bar chart in Figure 2.

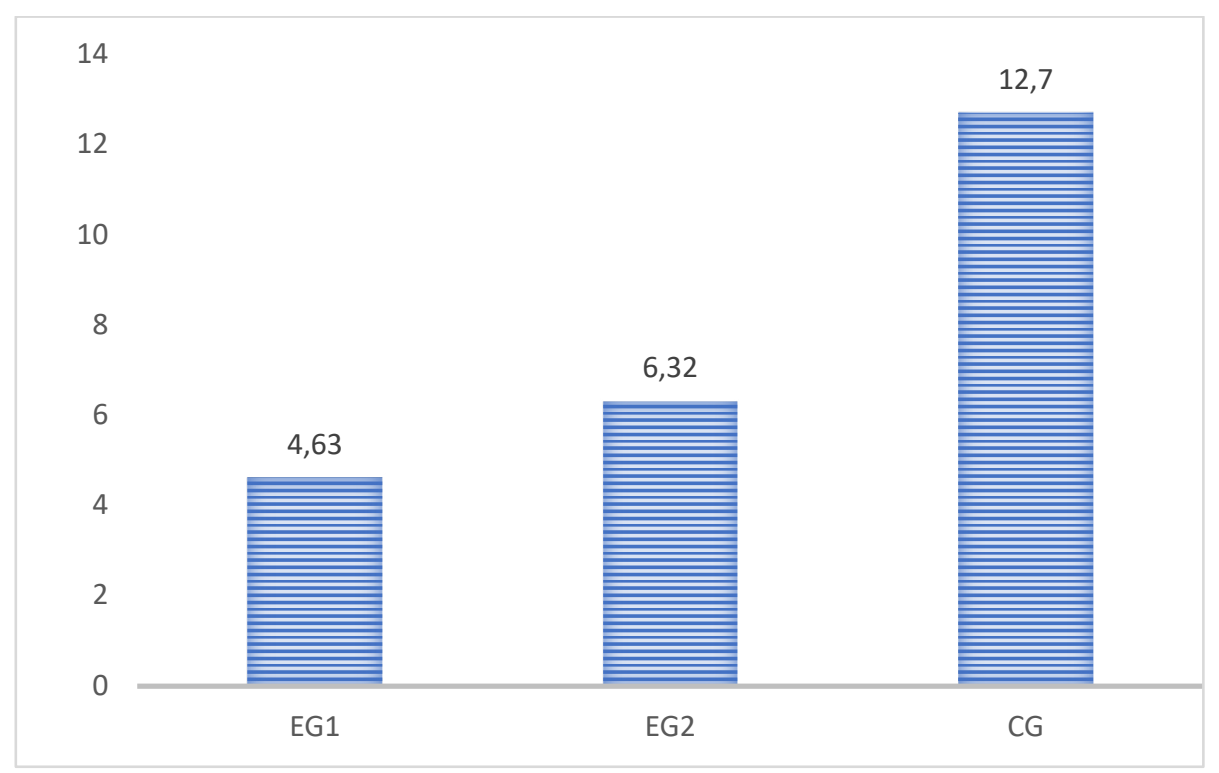

Figure 2. The accuracy mean scores of EG1, EG2, and CG on the posttest

\section{L2 writing Complexity}

The results of descriptive statistics for comparing the complexity posttest scores of the three groups of EG1, EG2, and CG are presented in Table 5:

Table 5. Descriptive statistics results comparing the EG1, EG2, and CG on complexity pretest scores

\begin{tabular}{lcccc}
\hline Groups & Mean & Adjusted Mean & Std. Deviation & N \\
\hline EG1 & 5.29 & 5.52 & 1.96 & 29 \\
EG2 & 4.20 & 4.18 & 1.87 & 25 \\
CG & 3.60 & 3.27 & 1.83 & 20 \\
\hline Total & 4.46 & 4.32 & 2.00 & 74 \\
\hline
\end{tabular}


Table 5 shows that the mean scores of the EG1 $(M=5.29)$, EG2 $(M=4.20)$, and CG $(M=3.60)$ were different from one another on the complexity posttest. To figure out whether the differences among these mean scores were statistically significant or not, the researcher had to check the $p$ value under the Sig. column in the row labeled Groups in the ANCOVA table (Table 6) below:

Table 6. Results of one-way ancova for comparing EG1, EG2, and CG on complexity posttest scores

\begin{tabular}{lcccccc}
\hline Source & $\begin{array}{c}\text { Type III Sum of } \\
\text { Squares }\end{array}$ & $d f$ & Mean Square & $F$ & Sig. & Partial Eta Squared \\
\hline Corrected Model & 152.29 & 3 & 50.76 & 25.40 & .00 & .52 \\
Intercept & 62.38 & 1 & 62.38 & 31.22 & .00 & .30 \\
Pretest & 115.69 & 1 & 115.69 & 57.89 & .00 & .45 \\
Groups & 61.02 & 2 & 30.51 & 15.27 & .00 & .30 \\
Error & 139.86 & 70 & 1.99 & & & \\
\hline Total & 1768.25 & 74 & & & & \\
\hline Corrected Total & 292.16 & 73 & & & & \\
\hline
\end{tabular}

As it is depicted in Table 6 , there was a statistically significant difference in the complexity posttest scores for EG1 $(M=5.29)$, EG2 $(M=4.20)$, and CG $(M=3.60)$ because the $p$ value under the Sig. column was in the row labeled Groups was smaller than the pre-specified level of significance $(.00<.05)$. To find out where exactly the differences among the three groups lay, the Bonferroni post hoc test was conducted, the results of which are in view in Table 7:

Table 7. Results of the bonferroni post hoc test for comparing EG1, EG2, and CG on complexity posttest scores

\begin{tabular}{lllllll}
\hline Groups & & Mean Difference & Std. Error & Sig. & \multicolumn{2}{c}{$95 \%$ Confidence Interval } \\
\hline \multirow{2}{*}{ EG1 } & & & & & Lower Bound & Upper Bound \\
& EG2 & $1.33^{*}$ & .38 & .00 & .38 & 2.28 \\
\multirow{2}{*}{ EG2 } & CG & $2.25^{*}$ & .41 & .00 & 1.22 & 3.27 \\
& EG1 & $-1.33^{*}$ & .38 & .00 & -2.28 & -.38 \\
\multirow{2}{*}{ CG } & CG & .91 & .42 & .10 & -.13 & 1.96 \\
& EG1 & $-2.25^{*}$ & .41 & .00 & -3.27 & -1.22 \\
\hline
\end{tabular}

In Table 7, it could be seen that the difference between EG1 $(M=5.29)$ and EG2 $(M=4.20)$ was statistically significant. This is so because the relevant $p$ value in front of EG1-EG2 comparison was lower than the alpha level of significance $(.00<.05)$. Likewise, the difference between EG1 learners and CG learners $(M=$ $3.60)$ on the complexity posttest was statistically significant $(p<.05)$. However, the difference between EG2 learners and the learners of the control group did not reach statistical significance. These obtained results are also shown in the bar chart in Figure 3: 


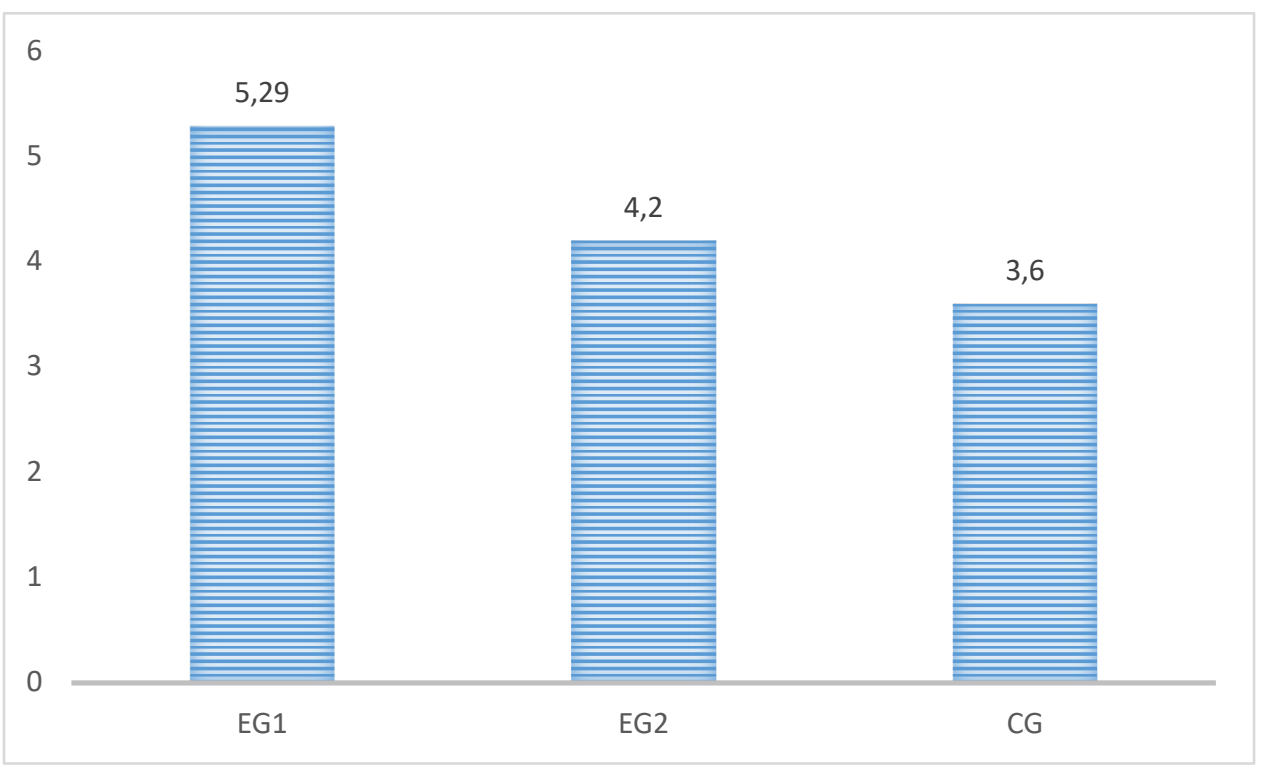

Figure 3. The complexity mean scores of EG1, EG2, and CG on the posttest

\section{L2 Writing Fluency}

The descriptive statistics results of the comparison of the fluency scores of the three groups on the posttest are shown in Table 8:

Table 8. Descriptive statistics results comparing EG1, EG2, and CG on fluency posttest scores

\begin{tabular}{lcccc}
\hline Groups & Mean & Adjusted Mean & Std. Deviation & $N$ \\
\hline EG1 & 4.99 & 4.90 & 1.33 & 29 \\
EG2 & 4.26 & 4.30 & .96 & 25 \\
CG & 4.25 & 4.34 & 1.26 & 20 \\
\hline Total & 4.55 & 4.51 & 1.23 & 74 \\
\hline
\end{tabular}

Table 8 shows that the fluency posttest mean scores of the EG1 $(M=4.99)$, EG2 $(M=4.26)$, and CG $(M$ $=4.25)$ differed from one another. To find out whether the differences among these fluency posttest mean scores were of statistical significance or not, the researcher had to look down the relevant $p$ value under the Sig. column Table 9:

Table 9. Results of one-way ANCOVA for comparing EG1, EG2, and CG on fluency posttest scores

\begin{tabular}{lcccccc}
\hline Source & $\begin{array}{c}\text { Type III Sum of } \\
\text { Squares }\end{array}$ & $d f$ & Mean Square & $F$ & Sig. & Partial Eta Squared \\
\hline Corrected Model & 35.13 & 3 & 11.71 & 10.64 & .00 & .31 \\
Intercept & 68.00 & 1 & 68.00 & 61.78 & .00 & .46 \\
Pretest & 25.59 & 1 & 25.59 & 23.25 & .00 & .24 \\
Groups & 5.86 & 2 & 2.93 & 2.66 & .07 & .07 \\
Error & 77.04 & 70 & 1.10 & & & \\
\hline Total & 1644.61 & 74 & & & & \\
\hline Corrected Total & 112.17 & 73 &
\end{tabular}


As it could be seen in Table 9, there was no statistically significant difference in fluency posttest mean scores for three groups of learners since the $p$ value under the Sig. column was larger than the specified level of significance $(.07>.05)$, which is also shown in the bar chart in Figure 4:

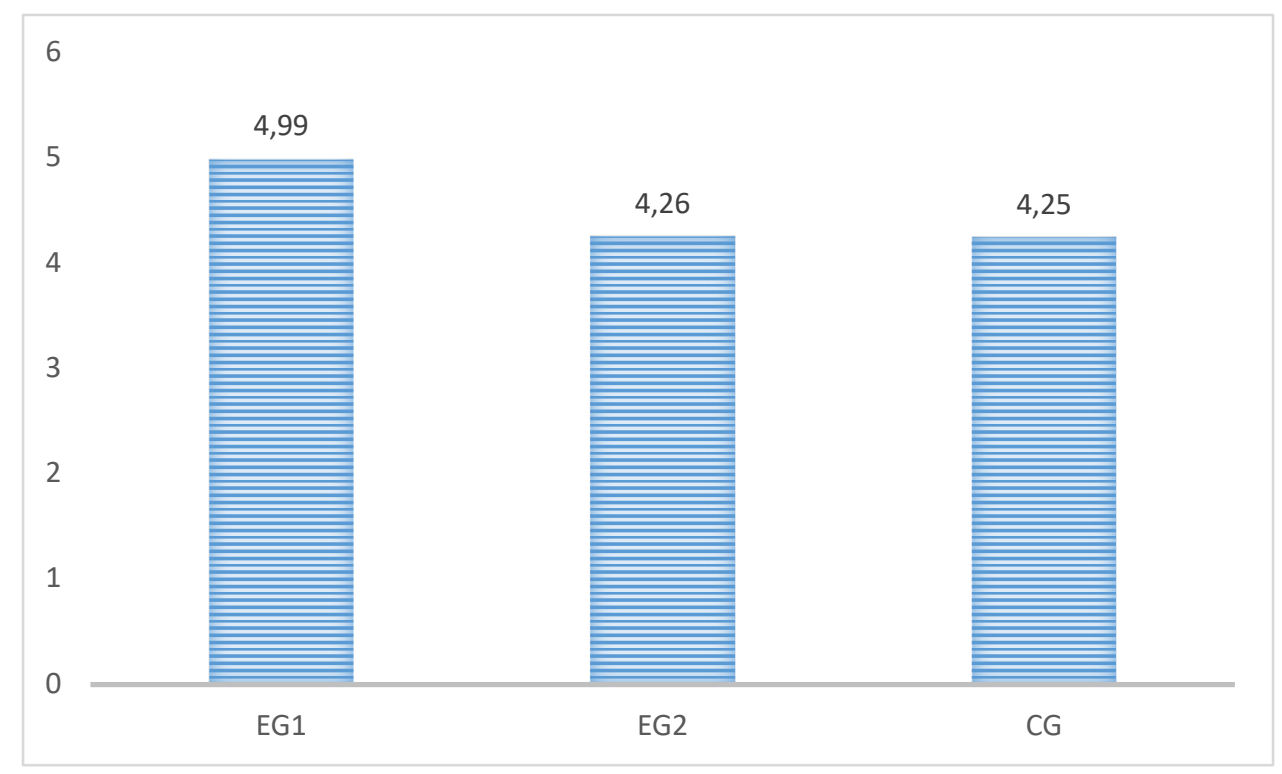

Figure 4. The fluency mean scores of EG1, EG2, and CG on the posttest

It is clear in Figure 4 that the EG1 learners had a mean score on the fluency posttest which was larger than the mean scores of the EG 2 and CG learners (who had roughly similar mean scores), but the differences were not considerable.

\section{DISCUSSION}

The research questions sought to examine the effects of applying online application devices for enhancing collaborative writing on writing performance of the learners, and to compare the written products of the learners as a group or individual work. The findings demonstrated that when the learners are provided with some instruments and facilities to write collaboratively outside the classroom environment, they outperform the time they write collaboratively only in the class. It is actually the same for those who write collaboratively in the class compared to individual writing. Actually, pair work and group work has widely been advocated so far and used in most institutions all around the world, however, asking students to compose a text in a process-oriented approach as a blended mode that is, both in the class and at home has almost remained a theory.

Following the social constructivists perspectives which claims pair work enhances writing performance among learners, the present study evaluated the learners' writing performance as far as their accuracy, complexity, and fluency are concerned. According to the Table 3, using online application devices afforded the learners to improve their accuracy. It shows that when the learners edit their peers' writing texts, they can foster attention to grammatical constructs and enhance their language learning. In fact, the learners need to have the ability to detect the grammatical errors in another texts. They are in a group with a sense of competition among the members and they share their comments on a platform where all other groups can see and read, therefore, as editors they do their best to perform it flawlessly. The benefits of editing are in fact threefold as far as improving the accuracy is concerned. The person who edits the text can learn during the editing activity, and the other member of the group with the role of writer who receives the comments can also benefit from it. Furthermore, the accuracy can be improved when the learners read the comments of the other groups and they would attempt to avoid such grammatical mistakes in their own writings. This result is line with Rybushkina \& Krasnova’s (2015) study in which they stated that the conventional face-to- 
face learning environment does not necessarily suit all students since each individual student has different learning abilities and does not necessarily share similar ways of learning with other students. Nevertheless, Internet-based pedagogy and online learning environments have been found to help students as well as teachers to overcome various problems in the learning and teaching of writing skills.

The second aspect of writing performance of the learners deals with the complexity. For the measure of complexity, the use of subordinate clauses was considered a crucial indicator of internal complexity in L2 writing performance of the participants. As can be seen in Table 6, both the participants in the e-learning project and the learners worked in groups in the class performed better. It can be inferred that when the learners spend more time on their tasks they can produce more complex sentences. In addition, the modifications they apply after editing stage can improve their writing ability as far as its complexity is concerned. Finally, these findings reveal that reading and reviewing each other's texts will be beneficial to enable the learners improve their writing skills. Mohammadi (2017) also showed that collaborative and e-collaborative tasks had improvement on interactional complexity of her learners. Besides, she stated that collaborative writing has more potential in fostering the development of interactional complexity.

The third aspect of writing performance evaluated in the present study is the fluency that the total number of words in the text were counted by the raters and then were divided by the total number of minutes it took to be written. According to the information provided in table 2.8, there is no significant difference between the participants who used online application devices and those who did not. There is also no significant changes between the second experimental group and the control group. These findings are compatible with the results of the study conducted by Storch (2005) concluded texts are shorter when they are written in pairs.

All in all, the findings reveal that when in-class learning activities blend with e-learning activities in different stages of writing process, from brainstorming to publishing, there is a significant improvement both in accuracy and complexity of the written products. The possible explanations might be that viewing the classmates' texts, taking more advantage of asynchronous mode of communication with more time at home, would help them expand the range of vocabulary and grammar they use. In addition, the various points having discussed in the class are available on the platform to review again and again by those who were present or absent in the class. Furthermore, the learners with lower proficiency levels sought help from the learners with higher proficiency levels in other groups whenever they were not able to reach a consensus over a problem.

Last but not least, the role of the teacher cannot be overlooked. The teacher monitors the groups and their activities continuously, and provides a careful plan for them. The learners must be provided with appropriate feedback when necessary to avoid any fossilizations.

\section{PEDAGOGICAL IMPLICATIONS}

The findings of the study may have some pedagogical implications. Accordingly, the results of the comparisons of the accuracy scores of the learners' writing products in collaborative and e-collaborative groups indicated a statistically significant difference. It can be implied that the learners not only need to work together to facilitate brainstorming stage in their writing but also improve their grammatical abilities after editing each other's texts. Therefore, the focus of the teachers in the writing courses must be on teacher evaluation, peer evaluation, and self-evaluation simultaneously, and the utilization of the technological advances can assist such evaluations. Similarly, Jafari and Nejad Ansari (2012) stated that collaborative writing can be beneficial for teachers in the sense that collaboration among students can result in more accurate texts as learners receive feedback from each other not just from their teacher.

Furthermore, the findings of the complexity scores of the learners can suggest new ideas for the teachers. According to some research, if a text uses more syntactically complex sentences than a written text which consists primarily of simple sentences, this text would be perceived more superior (Beers \& Nagy,2009; Saddler \& Graham, 2005). It is clear that the cooperation among the teacher and the students can facilitate the act of writing and analyzing different possible structures on the same topic. When students learn how to manage and control their writings, they would be able to produce different varieties of sentences in one written task. 
Finally, according to the findings of the fluency scores of the learners of this study, there is no improvement in the length of the written products. It shows that further research is required to find ways to enhance the fluency of the EFL learners' written products. One possible way to motivate the students to write longer essays or texts could be spending more time in the first stage of process writing. If they are given more time for brainstorming and organizing the ideas, they would be able to produce more details, examples and accordingly longer paragraphs. Therefore, the teachers who are interested in adopting the procedures performed in this study need to add more steps in the first stages of this writing process.

The results of this research can be useful for textbook developers, foreign language instructors and learners, especially at universities where there is no accurate assessment for placement of the students in a class. To this end, the instructors can benefit from the more advanced learners as facilitators amongst the students in a group. In addition, the teachers will understand the importance of collaboration for enhancing their students' cognitive development and they can use it in teaching and improving other skills such as speaking.

\section{CONCLUSION}

To sum up, this study aimed to investigate the impact of e-collaborative tasks on EFL learners' writing performance. The students in this research were instructed to write essays following process-oriented approach. According to the findings of the study, in a homogenous class at university the instructors can benefit from the more advanced learners as facilitators amongst the students in a group. In addition, the teachers will understand the importance of blending collaboration with online activities for enhancing their students' cognitive development and they can use it in teaching and improving other skills such as speaking.

Though the study had some limitations on the part of the participants and the course syllabus, it was difficult to ask the students to follow the steps at the beginning of the project and some of them were reluctant to do so. Most students prefer to write their assignments as quickly as possible no matter what the final product is. Moreover, the instructor had to follow the course syllabus and to cover specific parts which restricts the range of activities they can have during the course.

Acknowledgments: The authors wish to thank the second rater who spent her valuable time scoring the data and the students who participated in the study cooperating with the demanded requirements of the data gathering procedure.

\section{BIODATA and CONTACT ADDRESSES of AUTHORS}

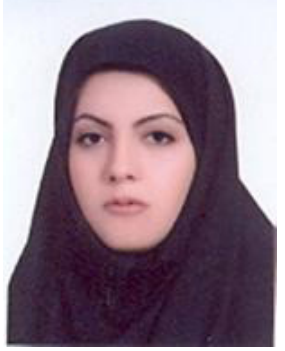

Nazli AZODI, got her BA in TEFL from Najafabad University, Isfahan, Iran in 1994. She got her MA in TEFL from Islamic Azad University, Isfahan (Khorasgan) Branch, Isfahan, Iran in 2007. She also got her PhD in TEFL from Islamic Azad University, Isfahan (Khorasgan) Branch. She is a faculty member of Islamic Azad University, Isfahan Branch since 2011. She has published 8 research articles in national and international journals. Her research interests are teacher education, teaching and learning strategies, and distance education.

Nazli AZODI

Department of Foreign Languages,

Address: Islamic Azad University, Isfahan (Khorasgan) Branch, 81595- 158, Isfahan, Iran

Phone: +989131011273

E-mail: azodi_n@yahoo.com 


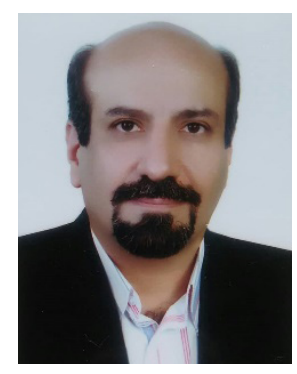

Ahmadreza LOTFI, received his PhD in TEFL from PhD center of Islamic Azad University in Tehran in 1997. He is an associate professor of TEFL in the Department of Foreign Languages, Isfahan (Khorasgan) Branch, Islamic Azad University, Isfahan, Iran. Dr. Lotfi has published about 80 research papers in national and indexed international journals. He has also published 5 books both in Persian and English mostly in Linguistics. He has been developing a radically minimialist theory of syntax. He has been teaching EFL learners and TEFL teachers for the last 28 years. His research interests include minimalist syntax, second language acquisition studies in generative grammar, and Iranian linguistics.

Ahmadreza LOTFI

Department of Foreign Languages

Address: Islamic Azad University, Isfahan (Khorasgan) Branch, 81595- 158, Isfahan, Iran

Phone: +989133178603

E-mail: lotfi.ahmadreza@gmail.com

\section{REFERENCES}

Abdulmajid, A. (2014). Scaffolding writing using Facebook in a blended learning ESL classroom. Unpublished Ph.D. thesis, The National University of Malaysia.

Adas, D., \& Bakir, A. (2013). Writing difficulties and new solutions: Blended learning as an approach to improve writing abilities. International Journal of Humanities and Social Science, 3(9), 254-266.

Al-Ahmad, S. (2003). The Impact of Collaborative Lerning on 11 and 12 College Students' Apprehension About and Attitudes Toward Writing. Unpublished Ph.D. thesis, Indiana University of Penneyivania.

Allen, N., Atkinson, D., Morgan, M., Moore, T. and Snow, C. (1987) 'What experienced collaborators say about collaborative writing'. Journal of Business and Technical Communication 1(2): 70-90.

Arslan, R. S. (2014). Integrating feedback into prospective English language teachers' writing process via blogs and portfolios. TOJET, 13(1), 131-150.

Beers, S. F., \& Nagy, W. E. (2009). Syntactic complexity as a predictor of adolescent writing quality: Which measures? Which genre? Reading and Writing: An Interdisciplinary Journal, 22 (2), 185-200.

Bronckart, J. P. (1995). Theories of action, speech, natural language, and discourse. In J. V. Wertsch, P. D. Rio \& A. Alvarez (Eds.), Sociocultural Studies of Mind (pp. 75- 91). New York: Cambridge University Press.

Cahyono, B. Y., \& Mutiaraningrum, I. (2016). Indonesian EFL Teachers' Familiarity with and Opinion on the Internet-Based Teaching of Writing. English Language Teaching, 9(1), 199-208. http://dx.doi. org/10.5539/elt.v9n1p199

Dalir, M., Jafarigohar, M., \& Soleimani, H. (2013) 'The Effect of Using Weblogs on Iranian EFL Learners Writing Skill'. International Journal of Language Learning and Applied Linguistics World (IJLLALW)

Ellis, R. (2009). The differential effects of three types of task planning on the fluency, complexity, and accuracy in L2 oral production. Applied Linguistics, 30, 474-509.

Ferris, D. (2006). 'Does error feedback help student writers? New evidence on the short- and long-term effects of written error correction'. In K. Hyland \& F. Hyland (Eds.), Feedback in second language writing (pp. 81-104). New York, NY: Cambridge University Press.

Flower, L., \& Hayes, J. R. (1981). 'A cognitive process theory of writing'. College Composition and Communication, 32(4), 365-387.

Ghoorchaei, B., Tavakoli, M., \& Nejad Ansari, D. (2010). 'The Impact of Portfolio Assessment on Iranian EFL Students' Essay Writing: A Process-oriented Approach'. GEMA online Journal of Language Studies. 10(3), 35-51.

Ghorbanpour, A. (2013). 'The Effect of Online Forum Participation on the EFL Learners' Writing Performance and Their Attitudes towards Learning English'. BARNOLIPI Journal.

Ghufron, M.A. (2016). 'Process-genre Approach, Product Approach, and Students' Self-esteem in Teaching Writing'. Indonesian EFL Journal: Journal of ELT, Linguistics, and Literature. Vol. 2, No. 1, pp. 37 - 54 
Grami, G. M. A. (2012). Online collaborative writing for ESL learners using blogs and feedback checklists. English Language Teaching, 5(10), 43-48.

Gunes, F. (2007). Turkce ogretimi ve zihinsel yapilandirma. Ankara: Nobel.

Hayes, J. R. (1996). A new framework for understanding cognition and affect in writing. In C. M. Levy \& S. Ransdell (Eds.), The science of writing: Theories, methods, individual differences, and applications (pp. 1-27). Mahwah, NJ: Lawrence Erlbaum.

Hosseinpour, N., Biria, R. (2014). 'Improving Iranian EFL Learners' Writing through Task-based Collaboration'. Theory and Practice in Language Studies, Vol. 4, No. 11, pp. 2428-2435.

Hussin, S., Abdullah, M. Y., Ismail, N., \& Yoke, S. K. (2015). The Effects of CMC Applications on ESL Writing Anxiety among Postgraduate Students. English Language Teaching, 8(9), 167-172. http:// dx.doi.org/10.5539/elt.v8n9p167

Hyland, K. (2003). 'Genre-based pedagogies: A social response to process'. Journal of Second Language Writing, 12: 17-29.

Jafari, N., Nejad Ansari, D. (2012). 'The Effect of Collaboration on Iranian EFL Learners' Writing Accuracy'. International Education Studies Vol. 5, No. 2.

Keshta, A. S., \& Harb, I. I. (2013). The effectiveness of a blended learning program on developing Palestinian tenth graders' English writing skills. Education Journal, 2(6), 208-221. http://dx.doi. org/10.11648/j.edu.20130206.12

Krasnova, T., \& Ananjev, A. (2015). Students' perception of learning in the online discussion environment. Mediterranean Journal of Social Sciences, 6(6 S1), 202-207. http://dx.doi.org/10.5901/mjss.2015. v6n6s1p202

Leki, I. (1991). 'The preferences of ESL students for error correction in college level writing classes'. Foreign Language Annals, 24, 203-218.

Leki, I. (2001). 'A narrow thinking system: Non-native English speaking students in group projects across the curriculum'. TESOL Quarterly, 35, 39- 57.

Maftoon, P., Ghafoori, N. (2009). 'A Comparative Study of the Effect of Homogeneous and Heterogeneous Collaborative Interaction on the Development of EFL Learners' Writing Skill'. The Journal of Applied Linguistics Vol. 2, Issue 1.

Mohammadi, Z. (2017). Interactional Complexity Development, Interactional Demonstrators and Interaction Density in Collaborative and e- collaborative Writing Modalities. Journal of Teaching Language Skills (JTLS)

Rybushkina, S., \& Krasnova, t. (2015). Key factors to use blended learning in teaching foreign languages in Russian engineering universities. EDULEARN15 Proceedings, 6886-6892.

Saddler, B., \& Graham, S. (2005). The effects of peer-assisted sentence-combining instruction on the writing performance of more and less skilled young writers. Journal of Educational Psychology, 97, 43-54.

Shafiee, S., Koosha, M., \& Afghari, A. (2013). The effect of conventional, Web-based, and Hybrid teaching of pre-writing strategies on Iranian EFL learners' writing performance. International Research Journal of Applied and Basic Sciences, 4(2), 393-401.

Shukor, S. S., \& Noordin, N. (2014). Effects of Facebook collaborative writing groups on ESL undergraduates' writing performance. International Journal of English Language Education, 2(2), 89-99. http:// dx.doi.org/10.5296/ijele.v2i2.5868

Storch, N. (2005). 'Collaborative writing: Product, process, and students' reflections'. Journal of second language writing, 14(3), 153-173. http://dx.doi.org/10.1016/j.jslw.2005.05.002

Taki, S., \& Fardafshari, E. (2012). Weblog-based collaborative learning: Iranian EFL learners' writing skill and motivation. International Journal of Linguistics, 4(2), 412-429. http://dx.doi.org/10.5296/ijl.v4i2.1663

Vygotsky, L. S. (1986). Thought and Language. Cambridge, MA: MIT Press.

Vygotsky LS (1978) Mind in Society: The Development of Higher Psychological Processes. Cambridge, MA: Harvard University Press.

Weigle, S. C. (2002). Assessing writing. Cambridge: Cambridge University Press. 


\section{APPENDIX}

\section{A Group Sample of E-collaborative Tasks}

Deleted Account
Group 11
First draft
What are the effects of TV? Can
TV have bad effects on the
audience and the society? what
do you think?
TV at the same time can have
good effects and bad effects. It
totally depends on your usage
and your view on this subject.
Although TV can have negative
effects such as taking the time
and have health damage, it can
also have a positive effect as
culture-building practices.
The first negative effect of TV
can be wasting time. If instead of
a lot of time snent watchina
Message

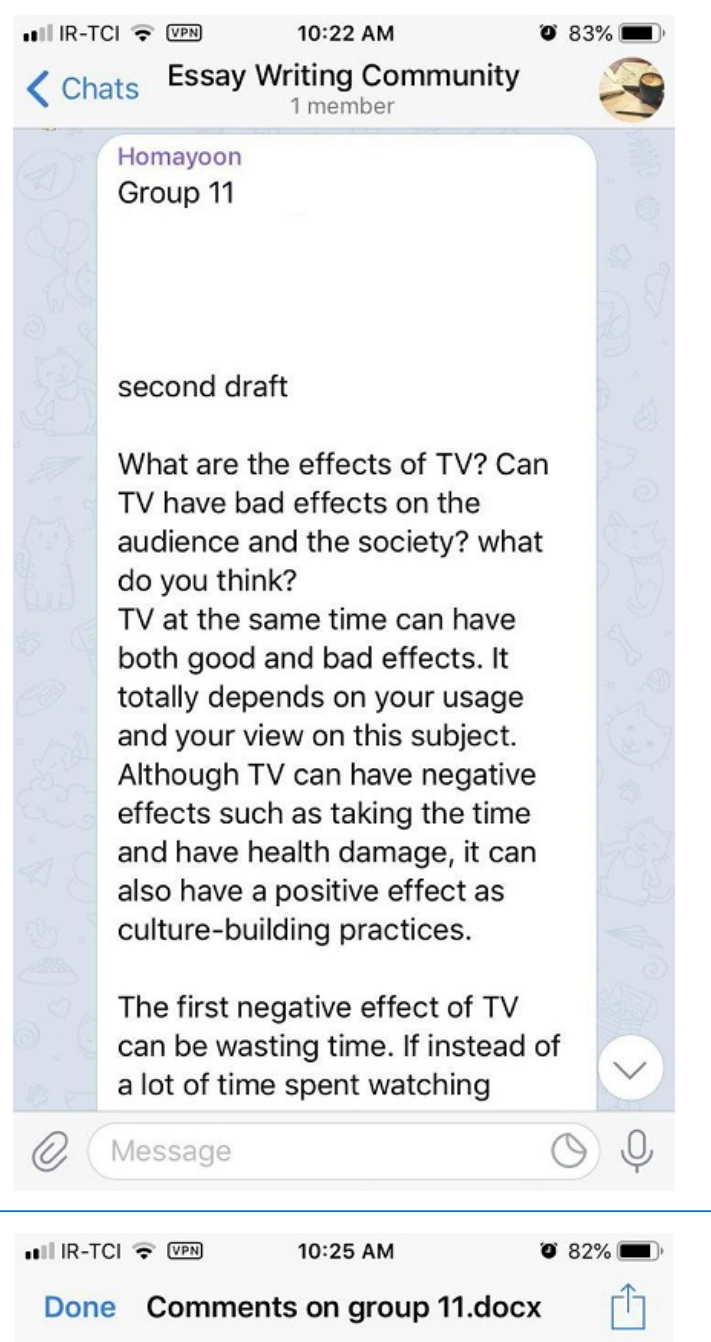

10:23 AM
Deleted Account
*pARTo*:
Group11's third draft
What are the effects of TV? Can
TV have bad effects on the
audience and the society? what
do you think?
TV at the same time can have
both good and bad effects. It
totally depends on your usage
and your view on this subject.
Although TV can have negative
effects such as taking the time
and having health issues, it can
also have a positive effect as
cultural developer.
The first negative effect of TV
can be wasting time. If instead of
a lot of time spending on
watching television do other
important affairs, obviously it will
be successul. Wasting too much
of time to watch TV may be falling
Message

What are the effects of TV? Can TV have bad effects on the audience and the society? what do you think? TV at the same time can have both good and bad effects. It totally depends on your usage and your view on this subject. Although TV can have negative effects such as taking the time and having health issuc,

The first negative effect of TV can be wasting time. If instead of a lot of time spending on watching television do other important uccessful. Wasting too much of time to watch TV may be falling behind the main tasks.

Second negative effect is damaging health too much watching TV is cause of eye issues/cataracts. and if it takes long time will be cause of demenia.

But one of the positive effect of watching TV is that it works for us like a cultural developer. Some television programs can have a positive impact on the community culture. Including educational programs and cooking programs. Some programs can also be in a positive direction entertained.

At the end as I said before, it really depends on your usage that TV has good or bad effects on your life and society. It has both good and bad effects, bad effects including waisting time and health problems, and as a good effects it includes culturebuilding practices.

The organization of your paragraph is really good. But your essay is too short!

Your second central paragraph is only a topic sentence!!!! Work on your grammar more. The editor should check more carefully. 